\title{
Comparison of short-term clinical outcomes between Resolute Onyx zotarolimus-eluting stents and everolimus-eluting stent in patients with acute myocardial infarction: Results from the Korea Acute Myocardial infarction Registry (KAMIR)
}

\author{
Yongcheol Kim ${ }^{1 *}$, Sung Sik $\mathrm{Oh}^{1 *}$, Myung Ho Jeong ${ }^{1}$, Youngkeun Ahn ${ }^{1}$, Ju Han Kim ${ }^{1}$, \\ Young Joon Hong ${ }^{1}$, Doo Sun $\mathrm{Sim}^{1}$, Min Chul Kim ${ }^{1}$, Hyo-Soo Kim ${ }^{2}$, Kyeong Ho Yun ${ }^{3}$, \\ Seok Kyu $\mathrm{Oh}^{3}$, Chong Jin $\mathrm{Kim}^{4}$, Myeong Chan $\mathrm{Cho}^{5}$; \\ other Korea Acute Myocardial Infarction Registry (KAMIR) Investigators \\ ${ }^{1}$ Chonnam National University Hospital, Gwangju, Republic of Korea
${ }^{2}$ Seoul National University Hospital, Seoul, Republic of Korea
${ }^{3}$ Wonkwang University Hospital, Iksan, Republic of Korea
${ }^{4}$ Kyung Hee University Hospital, Seoul, Republic of Korea
${ }^{5}$ Chungbuk National University Hospital, Cheongju, Republic of Korea
}

\begin{abstract}
Background: There are few studies which compare the efficacy and safety of the Resolute Onyx zotarolimus-eluting stent (O-ZES) and everolimus-eluting stent (EES) in patients with acute myocardial infarction (AMI). Therefore, the present study aimed to compare clinical outcomes of O-ZES and EES in patients with AMI undergoing successful percutaneous coronary intervention (PCI).

Methods: From January 2016 to December 2016, the Korea Acute Myocardial Infarction Registry (KAMIR) enrolled 3,364 consecutive patients. Among them, O-ZES was used in 402 patients and EES was used in 1,084 patients. The primary endpoint was target lesion failure (TLF), as defined by composite of cardiac death, target vessel myocardial infarction (TV-MI), and ischemic driven-target lesion revascularization (ID-TLR) at 6 month clinical follow-up.

Results: At 6 months, the incidence of TLF was not significantly different between O-ZES and EES group $(4.0 \%$ vs. $3.9 \%$, adjusted hazard ratio [HR] 1.17, 95\% confidential interval [CI] 0.58-2.35, $p=0.665)$. O-ZES also showed similar results of cardiac death (3.7\% vs. $3.4 \%$, adjusted HR $1.25,95 \%$ CI 0.59-2.63, $p=0.560)$, TV-MI (0.2\% vs. 0.6\%, adjusted HR 0.56, 95\% CI 0.07-4.85, $p=0.600)$, $\operatorname{ID}$-TLR $(0.0 \%$ vs. $0.3 \%, p=0.524)$, and definite or probable stent thrombosis $(0.2 \%$ vs. $0.3 \%$, adjusted HR 0.63, 95\% CI 0.06-6.41, $p=0.696$ ) when compared with EES.

Conclusions: The present study shows that implantation of O-ZES or EES provided similar clinical outcomes with similar risk at 6-month of TLF and definite/probable ST in patients with AMI undergoing successful PCI. (Cardiol J 2019; 26, 5: 469-476)
\end{abstract}

Key words: drug-eluting stents, myocardial infarction, percutaneous coronary intervention

Address for correspondence: Dr. Myung Ho Jeong, MD, PhD, FACC, FAHA, FESC, FSCAI, FAPSIC, Principal Investigator of Korea Acute Myocardial Infarction Registry, Heart Research Center, Chonnam National University Hospital, 671 Jaebongro, Dong-gu, Gwangju, 61469, Republic of Korea, tel: +82-62-220-6243, fax: +82-62-228-7174, e-mail: myungho@chollian.net Received: 4.02.2018 Accepted: 31.03.2018

*These authors contributed equally to this work. 


\section{Introduction}

Compared with bare-metal stents (BMS), drug-eluting stents (DES) have shown better clinical outcomes for patients undergoing percutaneous coronary intervention (PCI) by potent prevention from neointimal hyperplasia [1]. However, earlygeneration DES produced late thrombotic events, more than 1-year, by delaying arterial healing of stented vessels [2-5]. New-generation DES have developed with thinner stent struts, more biocompatible polymer coatings for drug release, and a variety of antiproliferative agents [6]. This development has led to a significant improvement in the efficacy and safety of early-generation DES. In recent years, new-generation DES replaced early-generation DES because of improved stent design, similar or superior anti-restenotic efficacy, and consistently lower rates of late stent thrombosis (ST) [7, 8]. In fact, currently used DES is a standard treatment in modern clinical procedures and is used by most patients undergoing PCI.

Currently, thin strut and durable polymerbased zotarolimus-eluting stent (ZES) and everolimus-eluting stent (EES) are widely used. Resolute Onyx-ZES (O-ZES), the latest version of ZES, has thinner strut, $81 \mu \mathrm{m}$, than ResoluteZES (R-ZES), prior version of ZES, which had $91 \mu \mathrm{m}$ of strut thickness. R-ZES and EES have been directly compared in several randomized trials powered for non-inferiority with respect to composite clinical endpoints [9-11]. However, there are few studies to compare the safety and efficacy of O-ZES and EES in patients with acute myocardial infarction (AMI). Therefore, the present study aimed to compare clinical outcomes of O-ZES and EES in patients with AMI undergoing successful PCI.

\section{Methods}

\section{Study design and patient population}

The Korea Acute Myocardial Infarction Registry (KAMIR) is a prospective multicenter registry providing observational online data collected and designed to examine characteristics, treatment practices, and outcomes in patients presenting AMI with the support of the Korean Circulation Society [12].

Study protocols were approved by the ethics committee at each participating center, and followed principles of the Declaration of Helsinki. Written informed consent was given by each patient. If patients were unable to give consent because of severity, informed consent was obtained from a relative or legal representative.

Among 3,364 patients enrolled in KAMIR between January 2016 and December 2016, a total of 1,486 patients with AMI were selected who had undergone successful PCI with O-ZES (Resolute Onyx $^{\mathrm{TM}}$, Medtronic Cardiovascular, Santa Rosa, CA) or EES (XIENCE ${ }^{\mathrm{TM}}$, Abbot Vascular Santa Clara, CA / SYNERGY ${ }^{\mathrm{TM}}$, Boston Scientific, Natick, MA). 402 patients with AMI were treated with O-ZES and 1,084 patients were treated with EES, 620 of $\mathrm{XIENCE}^{\mathrm{TM}}$ and 464 of SYNERGY ${ }^{\mathrm{TM}}$ (Fig. 1).

\section{Study endpoints, definitions,} and interventional procedures

The primary endpoint was target lesion failure (TLF), being defined as a composite of cardiac death, target vessel myocardial infarction (TV-MI), and ischemic driven-target lesion revascularization (ID-TLR) at 6 months clinical follow-up. The secondary endpoints were individual components of the TLF and definite/probable ST as defined by the Academic Research Consortium [13].

Death was regarded as cardiac in origin unless obvious non-cardiac causes could be identified. Myocardial infarction (MI) was defined as either the development of new pathological $\mathrm{Q}$ waves $\geq 0.04 \mathrm{~s}$ in duration in $\geq 2$ contiguous leads or an elevation of creatine phosphokinase levels to $>2$ times normal with positive creatine phosphokinase-MB or troponin I or T levels. TV-MI was defined as MI attributable to target vessel. TLR was considered ischemic-driven if associated with a positive functional study, a target lesion stenosis $\geq 50 \%$ by core laboratory quantitative analysis with ischemic symptoms or a target lesion stenosis $\geq 70 \%$ with or without documented ischemia.

Hypertension was defined as a history of hypertension diagnosed and treated with medication, diet and/or exercise, or blood pressure $>140$ $\mathrm{mmHg}$ systolic or $90 \mathrm{mmHg}$ diastolic on at least two occasions, or currently on antihypertensive pharmacologic therapy. Diabetes mellitus (DM) was defined as a history of DM, regardless of duration of disease, need for antidiabetic agents, or a fasting blood glucose $>126 \mathrm{mg} / \mathrm{dL}$. Family history of ischemic heart disease was indicated if the patient had any direct blood relatives (parents, siblings, children) who had any of the preceeding, which were diagnosed at age $<55$ years.

All patients who underwent PCI received $300 \mathrm{mg}$ acetylsalicylic acid (ASA) and 300 or $600 \mathrm{mg}$ clopidogrel, or prasugrel $60 \mathrm{mg}$, or ticagrelor $180 \mathrm{mg}$ as a loading dose prior to PCI. After PCI, 


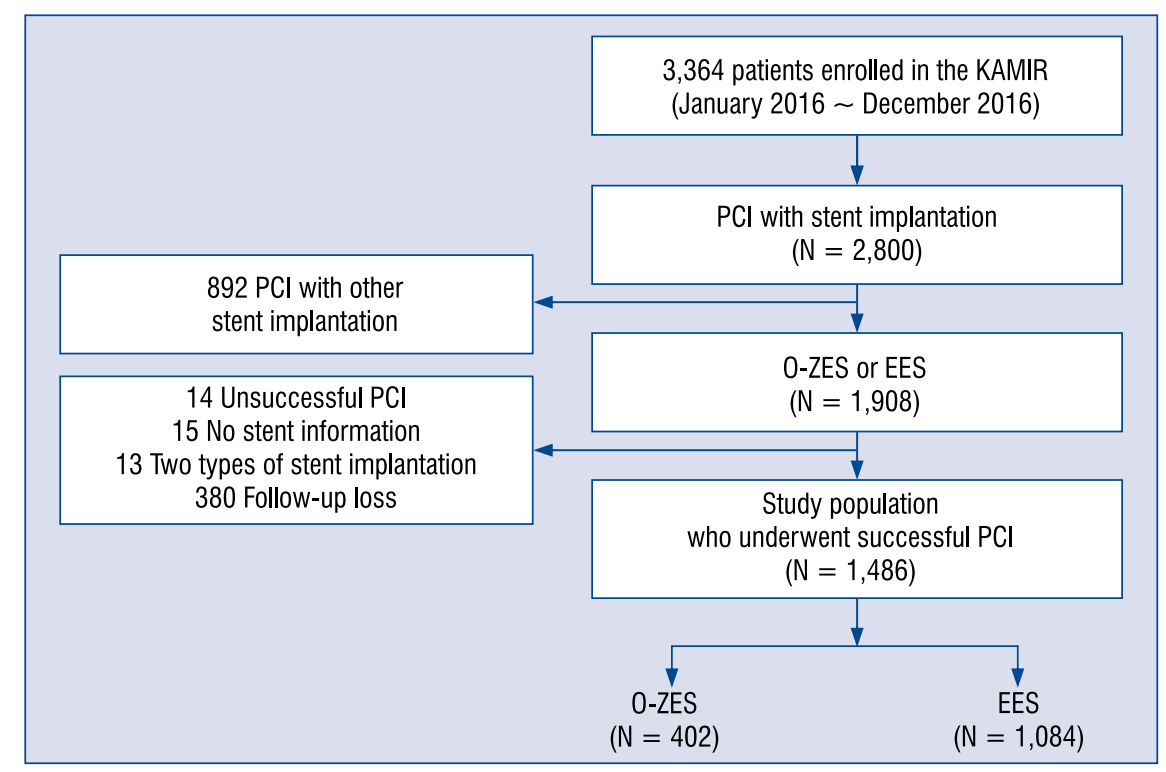

Figure 1. Patients flow chart, EES - everolimus-eluting stent; KAMIR - Korea Acute Myocardial Infarction Registry; O-ZES - Resolute Onyx zotarolimus-eluting stent; $\mathrm{PCl}$ - percutaneous coronary intervention.

100-300 mg ASA and $75 \mathrm{mg}$ clopidogrel, or 5 or $10 \mathrm{mg}$ prasugrel one daily or $90 \mathrm{mg}$ ticagrelor twice daily were prescribed for maintenance dose. Medication such as beta-blocker, angiotensin-converting enzyme inhibitor (ACEI) or angiotensin II receptor blocker (ARB), and statin were prescribed during hospitalization and after discharge. Coronary artery angiography and stent implantation were performed by standard methods. The selection of PCI timing, medication, vascular access, use of glycoprotein IIb/IIIa inhibitor, use of coronary stents were at physician discretion. Clinical follow-up was done at 6 months after enrollment.

\section{Statistical analysis}

All continuous variables were expressed as the mean with standard deviation (SD) or median with interquartile ranges (IQR), when appropriate. All categorical variables were reported as numbers with percentages. The continuous variables were compared using the unpaired t-test or Mann-Whitney $\mathrm{U}$ test, as appropriate. The categorical variables were analyzed by using a $\chi^{2}$ test or Fisher's exact test. The Cox proportional hazard regression modeling (with adjustment for covariates) was used to assess clinical outcomes. A Kaplan-Meier analysis was performed on data from the O-ZES and EES patient groups to compare 6-month TLF and cardiac death, and the difference was determined using a log-rank test. Variables had significance in univariate analysis $(\mathrm{p}<0.100)$ for endpoints which were included in multivariate analysis. The following variables were included in multivariate Cox regression analysis: age $\geq 65$, body mass index $\geq 25 \mathrm{~kg} / \mathrm{m}^{2}$, hypertension, DM, dyslipidemia, family history of ischemic heart disease, history of MI, history of angina, history of heart failure, history of cerebrovascular accident, Killip classification III/IV, left ventricular ejection fraction $\leq 50 \%$, left main or multivessel disease, image-guided PCI, ACC/ /AHA B2/C lesion, pre Thrombolysis In Myocardial Infarction (TIMI) flow grade $0 / 1$.

All analyses were two-tailed, and $\mathrm{p}$ value $<0.05$ was considered to reflect significance. All statistical analyses were performed using SPSS for Windows software (ver. 21.0; SPSS Inc., Chicago, IL, USA).

\section{Results}

A total of 1,486 patients with AMI underwent successful PCI were included in the present study. The average age of the total population was $64.1 \pm$ \pm 12.3 years and $75.4 \%$ were men. The mean stent diameter was $3.14 \pm 0.44 \mathrm{~mm}$ and the mean stent length was $30.6 \pm 15.1 \mathrm{~mm}$. The average number of stents used per vessel was $1.22 \pm 0.45$.

\section{Baseline characteristics and coronary angiographic findings}

Mean age was similar for the O-ZES and EES group $(64.2 \pm 12.2$ vs. $64.0 \pm 12.4, \mathrm{p}=0.802)$. The O-ZES group had higher prevalence of past his- 
Table 1. Baseline clinical and laboratory characteristics of patients in both groups.

\begin{tabular}{|c|c|c|c|}
\hline Variables & O-ZES $(n=402)$ & $\operatorname{EES}(n=1,084)$ & $\mathbf{P}$ \\
\hline \multicolumn{4}{|l|}{ Demographic: } \\
\hline Age [years] & $64.0 \pm 12.4$ & $64.2 \pm 12.2$ & 0.802 \\
\hline Male sex & $305(75.9 \%)$ & $816(75.3 \%)$ & 0.813 \\
\hline $\mathrm{BMI}\left[\mathrm{kg} / \mathrm{m}^{2}\right]$ & $24.2 \pm 3.5$ & $24.1 \pm 3.4$ & 0.832 \\
\hline \multicolumn{4}{|l|}{ Cardiovascular risk factors: } \\
\hline Hypertension & $206(51.2 \%)$ & $541(49.9 \%)$ & 0.647 \\
\hline Diabetes mellitus & $122(30.3 \%)$ & $294(27.1 \%)$ & 0.218 \\
\hline Dyslipidemia & $52(12.9 \%)$ & $128(11.8 \%)$ & 0.554 \\
\hline Current smoking & $158(39.3 \%)$ & $446(41.1 \%)$ & 0.521 \\
\hline Family history of IHD & $35(8.7 \%)$ & $106(9.8 \%)$ & 0.531 \\
\hline \multicolumn{4}{|l|}{ Medical history: } \\
\hline Angina & $36(9.0 \%)$ & $70(6.5 \%)$ & 0.097 \\
\hline Myocardial infarction & $30(7.5 \%)$ & $45(4.2 \%)$ & 0.010 \\
\hline Heart failure & $5(1.2 \%)$ & $11(1.0 \%)$ & 0.704 \\
\hline Cerebrovascular accident & $24(9.0 \%)$ & $73(6.7 \%)$ & 0.596 \\
\hline \multicolumn{4}{|l|}{ Vital sign on admission: } \\
\hline SBP $[\mathrm{mmHg}]$ & $131 \pm 29$ & $129 \pm 29$ & 0.191 \\
\hline $\mathrm{DBP}[\mathrm{mmHg}]$ & $78 \pm 18$ & $78 \pm 18$ & 0.641 \\
\hline Heart rate $[\mathrm{bpm}]$ & $79 \pm 19$ & $78 \pm 20$ & 0.474 \\
\hline STEMI & $207(51.5 \%)$ & $566(52.2 \%)$ & 0.805 \\
\hline Killip classification III/IV & $58(14.5 \%)$ & $151(14.5 \%)$ & 0.997 \\
\hline LVEF [\%] & $52.3(11.5 \%)$ & $52.8(11.2 \%)$ & 0.388 \\
\hline \multicolumn{4}{|l|}{ Laboratory findings: } \\
\hline Total cholesterol [mg/dL] & $174(146-203)$ & $177(145-206)$ & 0.965 \\
\hline Triglyceride $[\mathrm{mg} / \mathrm{dL}]$ & $110(81-151)$ & $110(78-162)$ & 0.360 \\
\hline HDL-cholesterol [mg/dL] & $41(35-52)$ & $42(35-49)$ & 0.466 \\
\hline LDL-cholesterol [mg/dL] & $109(86-133)$ & $111(85-138)$ & 0.461 \\
\hline Creatinine $[\mathrm{g} / \mathrm{dL}]$ & $0.9(0.8-1.1)$ & $0.9(0.8-1.1)$ & 0.292 \\
\hline hsCRP [mg/dL] & $0.30(0.14-1.07)$ & $0.30(0.14-1.20)$ & 0.689 \\
\hline Peak CK-MB [ng/mL] & $41(10-170)$ & $51.3(10-189)$ & 0.160 \\
\hline Peak troponin-I [ng/mL] & $18.9(4.1-40.0)$ & $22.8(4.8-40)$ & 0.990 \\
\hline
\end{tabular}

Data are expressed as median (interquartile range), mean \pm standard deviation or number (percentage) unless otherwise indicated; O-ZES - Resolute Onyx zotarolimus-eluting stent; EES — everolimus-eluting stent; BMI — body mass index; IHD — ischemic heart disease; SBP — systolic blood pressure; DBP - diastolic blood pressure; STEMI - ST-elevation myocardial infarction; LVEF — left ventricular ejection fraction; $\mathrm{HDL}$ — high-density lipoprotein; LDL — low-density lipoprotein; hsCRP — high-sensitivity C-reactive protein; CK — creatine kinase

tory of MI when compared with EES group (7.5\% vs. $4.2 \%, \mathrm{p}=0.010)$. In laboratory findings, there were no significant differences in either group. In terms of procedural characteristics, pre-PCI TIMI flow grade $0 / 1$ was higher in O-ZES group than in EES group (59.5\% vs. $53.2 \%, \mathrm{p}=0.028$ ). In angiographic findings, O-ZES group more frequently had left main or multivessel disease than in EES group ( $56.7 \%$ vs. $49.0 \%, p=0.008)$. ACEI/ARB was less prescribed in the O-ZES group than in the EES group $(73.6 \%$ vs. $78.9 \%, \mathrm{p}=0.032)$ (Tables 1,2$)$.

\section{Six-month clinical outcomes}

The 6-month clinical outcomes did not differ between the two groups as shown in Table 3. In Cox proportional hazard analysis, O-ZES also showed no statistical differences in the incidence of TLF ( $4.0 \%$ vs. $3.9 \%$, adjusted hazard ratio [HR] 1.17 , $95 \%$ confidential interval $[\mathrm{CI}] 0.58-2.35, \mathrm{p}=0.665$ ) (Fig. 2A), cardiac death (3.7\% vs. $3.4 \%$, adjusted HR $1.25,95 \%$ CI $0.59-2.63, \mathrm{p}=0.560$ ) (Fig. 2B), TV-MI $(0.2 \%$ vs. $0.6 \%$, adjusted HR $0.56,95 \%$ CI $0.07-4.85, \mathrm{p}=0.600)$, ID-TLR $(0.0 \%$ vs. $0.3 \%$, 
Table 2. Characteristics of coronary angiography, procedures and discharge medication between the two groups.

\begin{tabular}{|c|c|c|c|}
\hline Variables & O-ZES (n = 402) & EES $(n=1,084)$ & $\mathbf{P}$ \\
\hline Trans-radial access & $189(47.0 \%)$ & $498(46.3 \%)$ & 0.802 \\
\hline Image-guided PCl & $123(30.6 \%)$ & $359(33.1 \%)$ & 0.351 \\
\hline Glycoprotein Ilb/IIla inhibitor & $45(11.5 \%)$ & $163(15.2 \%)$ & 0.070 \\
\hline Pre-PCI TIMI flow grade $0 / 1$ & $237(59.5 \%)$ & $573(53.2 \%)$ & 0.028 \\
\hline Infarct-related artery: & & & 0.532 \\
\hline Left anterior descending & $186(46.3 \%)$ & $528(48.8 \%)$ & \\
\hline Left circumflex & $65(16.2 \%)$ & $180(16.6 \%)$ & \\
\hline Right coronary & $140(34.8 \%)$ & $337(31.1 \%)$ & \\
\hline Left main & $11(2.7 \%)$ & $38(3.5 \%)$ & \\
\hline Involved vessel type: & & & 0.008 \\
\hline Single vessel & $174(43.3 \%)$ & $551(51.0 \%)$ & \\
\hline Left main or multivessel & $228(56.7 \%)$ & $530(49.0 \%)$ & \\
\hline ACC/AHA B2/C lesion & $354(90.1 \%)$ & $952(89.3 \%)$ & 0.670 \\
\hline \multicolumn{4}{|l|}{ Implanted stent: } \\
\hline Stent number & $1.25 \pm 0.46$ & $1.20 \pm 0.45$ & 0.077 \\
\hline Stent diameter $[\mathrm{mm}]$ & $3.12 \pm 0.46$ & $3.15 \pm 0.43$ & 0.222 \\
\hline Stent length [mm] & $31.0 \pm 14.8$ & $30.4 \pm 15.2$ & 0.498 \\
\hline \multicolumn{4}{|l|}{ Medical treatment at discharge: } \\
\hline Acetylsalicylic acid & $393(97.8 \%)$ & $1,064(98.2 \%)$ & 0.626 \\
\hline P2Y12 receptor inhibitor: & $393(97.8 \%)$ & $1,060(97.8 \%)$ & 0.931 \\
\hline Clopidogrel & $200(50.6 \%)$ & $532(50.1 \%)$ & \\
\hline Ticagrelor & $170(43.0 \%)$ & $457(43.0 \%)$ & \\
\hline Prasugrel & $25(6.3 \%)$ & $73(6.9 \%)$ & \\
\hline Statin & $371(92.3 \%)$ & $1,021(94.2 \%)$ & \\
\hline ACEI/ARB & $296(73.6 \%)$ & $855(78.9 \%)$ & 0.032 \\
\hline Beta-blocker & $314(78.1 \%)$ & $863(79.6 \%)$ & 0.526 \\
\hline Calcium channel blocker & $34(8.5 \%)$ & $69(6.4 \%)$ & 0.158 \\
\hline
\end{tabular}

Data are expressed as mean \pm standard deviation or number (percentage) unless otherwise indicated; O-ZES - Resolute Onyx zotarolimuseluting stent; EES - everolimus-eluting stent; $\mathrm{PCl}$ - percutaneous coronary intervention; TIMI — Thrombolysis In Myocardial Infarction; ACC - American College of Cardiology; AHA - American Heart Association; ACEI - angiotensin-converting enzyme inhibitor; ARB - angiotensin II receptor blocker.

$\mathrm{p}=0.524)$, and definite/probable ST $(0.2 \%$ vs. $0.3 \%$, adjusted HR 0.63 , 95\% CI $0.06-6.41$, $\mathrm{p}=0.696$ ) when compared with EES (Table 3).

\section{Discussion}

There have been no studies to directly compare clinical outcomes between O-ZES and EES in specific high-risk groups, such as patients with AMI. This is the first multicenter and currently the largest observational study investigating clinical outcomes of AMI patients undergoing successful PCI with O-ZES or EES. The present study demonstrates that implantation of O-ZES or EES provided similar short-term clinical outcomes in patients with AMI undergoing successful PCI.
There are several studies regarding a comparison of clinical outcomes after PCI with R-ZES. In the RESOLUTE All Comers trial (A Randomized Comparison of a Zotarolimus-Eluting Stent with an Everolimus-Eluting Stent for Percutaneous Coronary Intervention), compared with the EES, the TLF did not significantly differ between R-ZES and EES in complex patients, such as AMI (8.9\% in R-ZES group vs. 9.7\% in EES group, $\mathrm{p}=0.66$ ) at 1-year follow-up [14]. In another randomized TWENTE trial, complex patients treated with R-ZES and EES showed similar TLF during 2-year follow-up (11.7\% in R-ZES group vs. $10.9 \%$ in EES group, $\mathrm{p}=0.68$ ) [15]. In these two randomized trials, however, patients with AMI were only $43.6 \%$ and $37.1 \%$, respectively, when compared with the 


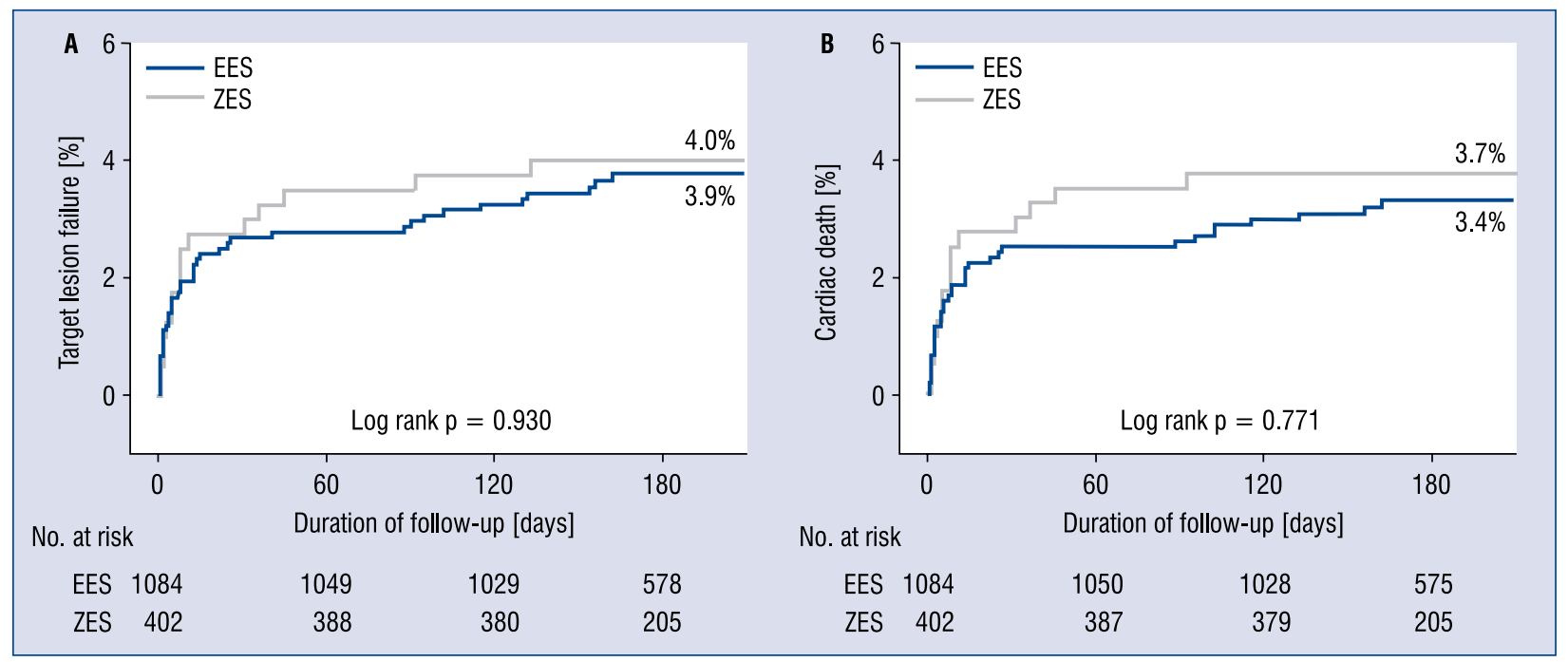

Figure 2. Kaplan-Meier curves for 6-month target lesion failure (A) and cardiac death (B) in patients with acute myocardial infarction; EES — everolimus-eluting stent; ZES — zotarolimus-eluting stent.

Table 3. Six-month cumulative clinical outcomes in both groups.

\begin{tabular}{|c|c|c|c|c|c|c|c|c|}
\hline & \multirow{2}{*}{$\begin{array}{c}\text { O-ZES } \\
(n=402)\end{array}$} & \multirow{2}{*}{$\begin{array}{c}\text { EES } \\
(n=1,084)\end{array}$} & \multicolumn{3}{|c|}{ Unadjusted } & \multicolumn{3}{|c|}{ Adjusted } \\
\hline & & & HR & $95 \% \mathrm{Cl}$ & $\mathbf{P}$ & HR & $95 \% \mathrm{Cl}$ & $\mathbf{P}$ \\
\hline Target lesion failure & $16(4.0 \%)$ & $42(3.9 \%)$ & 1.03 & $0.58-1.83$ & 0.930 & 1.17 & $0.58-2.35$ & 0.665 \\
\hline Cardiac death & $15(3.7 \%)$ & $37(3.4 \%)$ & 1.09 & $0.60-1.99$ & 0.771 & 1.25 & $0.59-2.63$ & 0.560 \\
\hline TV-MI & $1(0.2 \%)$ & $6(0.6 \%)$ & 0.45 & $0.05-3.71$ & 0.456 & 0.56 & $0.07-4.85$ & 0.600 \\
\hline ID-TLR & $0(0.0 \%)$ & $3(0.3 \%)$ & & & 0.524 & & & \\
\hline Definite/probable ST & $1(0.2 \%)$ & $3(0.3 \%)$ & 0.92 & $0.10-8.79$ & 0.938 & 0.63 & $0.06-6.41$ & 0.696 \\
\hline
\end{tabular}

Data are expressed as number (percentage). O-ZES - new developed Resolute Onyx zotarolimus-eluting stent; EES - everolimus-eluting stent; HR - hazard ratio; $\mathrm{Cl}$ — confidence interval; TV-MI — target vessel myocardial infarction; ischemic driven-target lesion revascularization; ST — stent thrombosis

present study which enrolled all patients with AMI. ST-elevation myocardial infarction (STEMI) patients receiving R-ZES had similar 5-year clinical outcomes as compared with those receiving EES in the RESOLUTE All Comers trial (TLF, $7.6 \%$ in R-ZES group vs. $10.4 \%$ in EES group, adjusted $\mathrm{p}=0.123$; definitive/probable ST, $0.8 \%$ in R-ZES group vs. $1.3 \%$ in EES group, adjusted $\mathrm{p}=0.868$ ) [16]. In the RESOLUTE Global Clinical Trial Program comprising 10 prospective trials, R-ZES showed good long-term clinical outcomes. In 7618 patients treated with R-ZES, the 5-year cumulative incidence of TLF was $13.4 \%$, cardiac death 5.0\%, TV-MI 4.4\%, and ID-TLR 6.3\% [17]. In the RESOLUTE Global Clinical Trial Program, STEMI patients treated with R-ZES also had good 3 -year clinical outcomes, including TLF 9.8\%, cardiac death $2.9 \%$, TV-MI $1.6 \%$, ID-TLR $7.0 \%$, and definite/probable ST 2.8\% [16].
Regarding the safety and efficacy of O-ZES, O-ZES showed 1-year TLF rate of $4.4 \%$ and similar efficacy and safety compared with most contemporary DES [18]. O-ZES demonstrated superiority for 8-month in-stent late lumen loss compared with the historical control R-ZES in the RESOLUTE ONYX core trial $(0.24 \pm 0.39 \mathrm{~mm}$ with O-ZES vs. $0.36 \pm 0.52 \mathrm{~mm}$ with R-ZES, $\mathrm{p}=0.029$ ) [19]. Moreover, $2.0 \mathrm{~mm}$ O-ZES was associated with a low rate of TLF and late lumen loss without definite/ probable ST at 12 month follow-up for treatment of coronary lesions with a very small reference vessel diameter, less than $2.25 \mathrm{~mm}$ in the recent study [20]. These favorable clinical outcomes including angiographic benefit of O-ZES could be explained by characteristics of O-ZES. O-ZES has a swaged shape and a larger strut width-to-thickness ratio (strut width $91 \mu \mathrm{m}$ and thickness $81 \mu \mathrm{m}$ ) to maintain radial strength despite thinner strut 
when compared with R-ZES. O-ZES also has a dense inner core composed of the platinum-iridium alloy for increased radiopacity. The enhanced radiopacity of O-ZES might have contributed to less geographic miss which was associated with increased target vessel revascularization [21].

\section{Limitations of the study}

There were several limitations in the present study. First, it was a retrospective study and there were possibilities for selection bias. Therefore multivariate analysis was undertaken to overcome these limitations. Secondly, the number of patients included in O-ZES group was relatively small, and thus, this study is less robust because of the small sample size. Thirdly, EES group included durable polymer everolimus-eluting stent $\left(\mathrm{XIENCE}^{\mathrm{TM}}\right)$ and bioresorbable polymer everolimus-eluting stent $\left(\mathrm{SYNERGY} \mathrm{T}^{\mathrm{TM}}\right)$. Differing stent features can be a possible confounding factor. Finally, interval of follow-up was too short to analyze long-term clinical outcomes. Thus, more extensive and long-term data are needed.

\section{Conclusions}

This study shows that implantation of O-ZES or EES provided similar clinical outcomes with similar risk of 6-month TLF and definite/probable ST in patients with AMI undergoing successful PCI.

\section{Acknowledgements}

This study was performed with the support of the Korean Circulation Society (KCS) as a memorandum of the $50^{\text {th }}$ Anniversary of KCS and the Korean Ministry of Health and Welfare, Republic of Korea.

\section{Conflict of interest: None declared}

\section{References}

1. Stefanini GG, Holmes DR. Drug-eluting coronary-artery stents. N Engl J Med. 2013; 368(3): 254-265, doi: 10.1056/NEJMra1210816, indexed in Pubmed: 23323902.

2. Wenaweser P, Daemen J, Zwahlen M, et al. Incidence and Correlates of Drug-Eluting Stent Thrombosis in Routine Clinical Practice. J Am Coll Cardiol. 2008; 52(14): 1134-1140, doi: 10.1016/j. jacc.2008.07.006.

3. Windecker S, Meier B. Late coronary stent thrombosis. Circulation. 2007; 116(17): 1952-1965, doi: 10.1161/CIRCULATIONAHA.106.683995, indexed in Pubmed: 17965406.

4. Windecker S, Jüni P. Safety of drug-eluting stents. Nat Clin Pract Cardiovasc Med. 2008; 5(6): 316-328, doi: 10.1038/ncpcardio1189, indexed in Pubmed: 18414453.
5. Joner M, Finn A, Farb A, et al. Pathology of Drug-Eluting Stents in Humans. J Am Coll Cardiol. 2006; 48(1): 193-202, doi: 10.1016/j.jacc.2006.03.042.

6. Stefanini GG, Taniwaki M, Windecker S. Coronary stents: novel developments. Heart. 2014; 100(13): 1051-1061, doi: 10.1136/ /heartjnl-2012-303522, indexed in Pubmed: 24006453.

7. Sarno G, Lagerqvist Bo, Fröbert O, et al. Lower risk of stent thrombosis and restenosis with unrestricted use of 'new-generation' drug-eluting stents: a report from the nationwide Swedish Coronary Angiography and Angioplasty Registry (SCAAR). Eur Heart J. 2012; 33(5): 606-613, doi: 10.1093/eurheartj/ehr479, indexed in Pubmed: 22232428.

8. Räber L, Magro M, Stefanini GG, et al. Very late coronary stent thrombosis of a newer-generation everolimus-eluting stent compared with early-generation drug-eluting stents: a prospective cohort study. Circulation. 2012; 125(9): 1110-1121, doi: 10.1161/CIRCULATIONAHA.111.058560, indexed in Pubmed: 22302840.

9. Kang SH, Park KW, Kang DY, et al. Biodegradable-polymer drug-eluting stents vs. bare metal stents vs. durable-polymer drug-eluting stents: a systematic review and Bayesian approach network meta-analysis. Eur Heart J. 2014; 35(17): 1147-1158, doi: 10.1093/eurheartj/eht570, indexed in Pubmed: 24459196.

10. Navarese EP, Tandjung K, Claessen B, et al. Safety and efficacy outcomes of first and second generation durable polymer drug eluting stents and biodegradable polymer biolimus eluting stents in clinical practice: comprehensive network meta-analysis. BMJ. 2013; 347: f6530, indexed in Pubmed: 24196498.

11. Palmerini T, Biondi-Zoccai G, Della Riva D, et al. Clinical outcomes with bioabsorbable polymer- versus durable polymer-based drug-eluting and bare-metal stents: evidence from a comprehensive network meta-analysis. J Am Coll Cardiol. 2014; 63(4): 299-307, doi: 10.1016/j.jacc.2013.09.061, indexed in Pubmed: 24211507.

12. Kim JH, Chae SC, Oh DJ, et al. Multicenter Cohort Study of Acute Myocardial Infarction in Korea - Interim Analysis of the Korea Acute Myocardial Infarction Registry-National Institutes of Health Registry. Circ J. 2016; 80(6): 1427-1436, doi: 10.1253/ /circj.CJ-16-0061, indexed in Pubmed: 27118621.

13. Cutlip DE, Windecker S, Mehran R, et al. Clinical end points in coronary stent trials: a case for standardized definitions. Circulation. 2007; 115(17): 2344-2351, doi: 10.1161/CIRCULATIONAHA.106.685313, indexed in Pubmed: 17470709.

14. Stefanini GG, Serruys PW, Silber S, et al. The impact of patient and lesion complexity on clinical and angiographic outcomes after revascularization with zotarolimus- and everolimus-eluting stents: a substudy of the RESOLUTE All Comers Trial (a randomized comparison of a zotarolimus-eluting stent with an everolimus-eluting stent for percutaneous coronary intervention). J Am Coll Cardiol. 2011; 57(22): 2221-2232, doi: 10.1016/j. jacc.2011.01.036, indexed in Pubmed: 21616282.

15. Sen H, Lam MK, Tandjung K, et al. Complex patients treated with zotarolimus-eluting resolute and everolimus-eluting Xience $\mathrm{V}$ stents in the randomized TWENTE trial: comparison of 2-year clinical outcome. Catheter Cardiovasc Interv. 2015; 85(1): 74-81, doi: 10.1002/ccd.25464, indexed in Pubmed: 24585502.

16. Di Mario C, Serruys PW, Silber S, et al. Long-term outcomes after Resolute zotarolimus-eluting stent implantation in patients with ST-segment elevation acute myocardial infarction: insights from the RESOLUTE All Comers Trial and the RESOLUTE Global Clinical Trial Program. EuroIntervention. 2016; 12(10): 
1207-1214, doi: 10.4244/EIJV12I10A199, indexed in Pubmed: 27866129.

17. Yeh RW, Silber S, Chen L, et al. 5-Year safety and efficacy of resolute zotarolimus-eluting stent: the RESOLUTE global clinical trial program. JACC Cardiovasc Interv. 2017; 10(3): 247-254, doi: 10.1016/j.jcin.2016.11.004, indexed in Pubmed: 28109872.

18. Tam CC, Chan K, Lam S, et al. One-year clinical outcomes of patients implanted with a Resolute Onyx ${ }^{\mathrm{TM}}$ zotarolimus-eluting stent. J Int Med Res. 2018; 46(1): 457-463, doi: 10.1177/0300060517717826, indexed in Pubmed: 28758853.

19. Price MJ, Shlofmitz RA, Spriggs DJ, et al. Safety and efficacy of the next generation Resolute Onyx zotarolimus-eluting stent: Primary outcome of the RESOLUTE ONYX core trial. Cath- eter Cardiovasc Interv. 2017 [Epub ahead of print], doi: 10.1002/ /ccd.27322, indexed in Pubmed: 28940882.

20. Price MJ, Saito S, Shlofmitz RA, et al. First Report of the Resolute Onyx 2.0-mm Zotarolimus-Eluting Stent for the Treatment of Coronary Lesions With Very Small Reference Vessel Diameter. JACC Cardiovasc Interv. 2017; 10(14): 1381-1388, doi: 10.1016/j.jcin.2017.05.004, indexed in Pubmed: 28728650.

21. Costa MA, Angiolillo DJ, Tannenbaum M, et al. STLLR Investigators. Impact of stent deployment procedural factors on long-term effectiveness and safety of sirolimus-eluting stents (final results of the multicenter prospective STLLR trial). Am J Cardiol. 2008; 101(12): 1704-1711, doi: 10.1016/j.amjcard.2008.02.053, indexed in Pubmed: 18549844. 